\title{
Antioxidant, $\alpha$-Glucosidase Inhibitory Activity and Molecular Docking Study of Gallic Acid, Quercetin and Rutin: A Comparative Study
}

\author{
Agus Limanto ${ }^{1}$, Adelina Simamora ${ }^{1}$, Adit Widodo Santoso², Kris Herawan Timotius ${ }^{1}$ \\ ${ }^{1}$ Department of Biochemistry, Krida Wacana Christian University, Jakarta, Indonesia \\ ${ }^{2}$ Department of Herbal Medicine, Krida Wacana Christian University, Jakarta, Indonesia
}

Background: Plant-phenolics and flavonoids, including gallic acid, quercetin and rutin, are considered as safe inhibitors for $\alpha$-glucosidase. This study aimed to compare antioxidant and $\alpha$-glucosidase inhibitory activities of gallic acid (GA), quercetin (QUE) and rutin (RUT).

Materials and Methods: Pure compounds of GA, QUE, and RUT were used. Their antioxidant and inhibitory activity on $\alpha$-glucosidase were investigated spectroscopically, including their kinetic analysis and interaction mechanism by docking simulation.

Results: All the tested compounds (GA, QUE, and RUT) showed good antioxidant activity better than the standards ascorbic acid (AA) and butylated hydroxytoluene (BHT), with QUE showing the highest antioxidant activity based on 2,2-diphenyl1-picrylhydrazyl (DPPH) radical scavenging activity. Based on their reducing properties, the activities of the compounds follow the following order: AA > GA > BHT > QUE > RUT. Both GA and RUT induced a competitive type of inhibition, with activities stronger than acarbose $\left(\mathrm{IC}_{50}=823 \mu \mathrm{g} / \mathrm{mL}\right)$, whereas QUE inhibited in a mixed type manner. The $\mathrm{IC}_{50}$ of GA, QUE, and RUT were $220.12,65.52$, and $224.55 \mu \mathrm{g} / \mathrm{mL}$ respectively. The results obtained from molecular docking indicate that all compounds have affinity in the active site pocket of $\alpha$-glucosidase, with the hydrogen bond being the major force involved in each compound binding to the enzyme.

Conclusion: In conclusion, QUE has better antioxidant and $\alpha$-glucosidase inhibitory activity than GA and RUT. This work provides insights into the interactions between GA, QUE, and RUT and $\alpha$-glucosidase.

Keywords: docking, gallic acid, $\alpha$-glucosidase, rutin, quercetin

\section{Introduction}

Plant products are potentially a good source for screening $\alpha$-glucosidase inhibitors. Flavonoids and phenolics which are widely existed in various plants have been reported to exhibit inhibitory effect on $\alpha$-glucosidase, such as luteolin ${ }^{1}$, kaempferol ${ }^{2}$ and gallic acid (GA) ${ }^{3}$. GA, quercetin (QUE) and rutin (RUT) are commonly used as standard compounds for

Date of submission: January 31, 2019

Last Revised: February 22, 2019

Accepted for publication: February 22, 2019

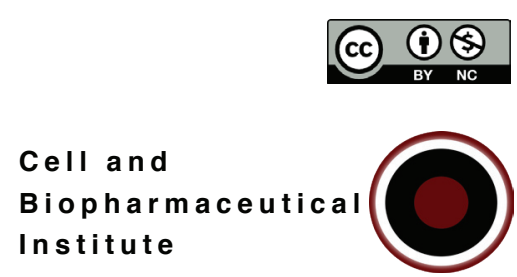

Corresponding Author:

Adelina Simamora

Department of Biochemistry

Krida Wacana Christian University

Jl. Terusan Arjuna Utara No 6, Jakarta, Indonesia

E-mail: adelina.simamora@ukrida.ac.id 
total phenolic and/or total flavonoid measurements. Their inhibitory activities on $\alpha$-glucosidase are not yet compared experimentally. In the present study, the antioxidant capacities and $\alpha$-glucosidase inhibitory activities of these compounds, including their type of inhibitions and binding interactions with the enzyme were reported.

GA or 3,4,5-trihydroxybenzoic acid (Figure 1) is a plant-derived phenolic acid. GA exerts many biological effects such as antioxidant, anticancer, antiviral, cardioprotective and anti-diabetic effects. ${ }^{4,5} \mathrm{GA}$ showed strong antidiabetic activity both in vitro and in vivo ${ }^{6}$ and its combination with acarbose was recommended for antidiabetic therapy. ${ }^{3}$ Moreover, derivates of GA i.e., methyl gallate and propyl gallate showed strong $\alpha$-glucosidase inhibitory activity., GA extracted from plants have been shown to exert strong inhibition on $\alpha$-glucosidase. ${ }^{8,9}$

QUE is a kind of plant flavonoid, whereas RUT is a glycoside of QUE (Figure 1). QUE and RUT belong to flavonol which are often found in onion, kale, broccoli, apples, cherries, berries, black tea, and mango. ${ }^{10,11}$ Both were reported to possess anti-diabetic potentials. ${ }^{12,13}$ Some studies proposed that QUE and RUT exerts its hypoglycemic effect through multiple actions including by increasing the proliferation of pancreatic $\beta$-cells, enhancing insulin sensitivity and stimulating insulin secretion. ${ }^{12,14}$ Further, antidiabetic effect of QUE may also involve the protection of $\beta$-cells, as were shown by previous in vivo studies. ${ }^{15} \mathrm{In}$ addition, QUE and RUT were shown to strongly inhibit $\alpha$-glucosidase. ${ }^{16}$

The aims of this study were to determine and compare inhibitory activities of GA, QUE and RUT on $\alpha$-glucosidase and to investigate their binding interaction with the enzyme by in vitro and molecular docking studies. Their antioxidant capacities were also evaluated.

\section{Materials and methods}

The 2,2-diphenyl-1-picrylhydrazyl (DPPH) Free Radical Scavenging Activity Assay

Antioxidant activities of GA (Cat. No. \#sc205704, Santa Cruz Biotechnology, Dallas, USA), QUE (Cat. No. \#PHR1488, Sigma-Aldrich, St Louis, USA), RUT (Cat. No. \#sc204897B, Santa Cruz Biotechnology) and standard compounds, ascorbic acid (AA) (Cat. No. \#470300-286, VWR BDH Prolabo Chemicals, Lutterworth, UK) and butylated hydroxytoluene (BHT) (Cat. No. \#B1378, SigmaAldrich) were determined based on reported method. ${ }^{17}$ Solution of DPPH (Cat. No. \#D9132, Sigma-Aldrich) (0.6 $\mathrm{mM}$ in ethanol) was prepared and $1 \mathrm{~mL}$ of this solution was added to $3 \mathrm{~mL}$ of tested compounds at various concentration. The reactions were incubated for $30 \mathrm{~min}$ in darkness at room temperature and the absorbance was read at $517 \mathrm{~nm}$<smiles>COCC1=CC(NC2C(C)OC(OC3C(CO)OC(OC4C(CO)OC(O)C(O)C4O)C(O)C3O)C(O)C2O)C(O)C(O)C1O</smiles><smiles>CC1OC(OCC2OC(Oc3c(-c4ccc(O)c(O)c4)oc4cc(O)cc(O)c4c3=O)C(O)C(O)C2O)C(O)C(O)C1O</smiles>

Figure 1. Molecular structures of acarbose (A), GA (B), QUE (C) and RUT (D). 
with spectrophotometer Biochrom Libra S-22 (Biochrom, Cambridge, UK). Ethanol (3 $\mathrm{mL})$ in place of extract was used as control. The percentage inhibition activity was calculated according to the following equation:

$$
\underset{\text { scavenging activity }(\%)}{\mathrm{DPPH} \text { radical }}=\frac{\mathrm{A}_{\text {control }}-\mathrm{A}_{\text {sample }}}{\mathrm{A}_{\text {control }}} \times 100 \%
$$

Where $\mathrm{A}_{\text {control }}$ : absorbance of control, $\mathrm{A}_{\text {sample }}$ : absorbance of sample. The percentage of inhibition was plotted against concentration to calculate the $\mathrm{IC}_{50}$ which is defined as the amount of antioxidant required to decrease the inhibition of $\mathrm{DPPH}$ radical by $50 \%$. The $\mathrm{IC}_{50}$ values were expressed as $\mu \mathrm{g} / \mathrm{mL}$ and compared with the standards.

\section{Reducing Power Activity Assay}

Reducing power capacity of GA, QUE, and RUT was determined according to reported method. ${ }^{18}$ The procedure was based on the reduction of $\mathrm{Fe}$ (III) to $\mathrm{Fe}$ (II) reaction. Different concentrations of compounds or standards (ascorbic acid and BHT) in water $(50,100$, and $200 \mu \mathrm{g} /$ $\mathrm{mL}$ ) were prepared. In a test tube, $1 \mathrm{~mL}$ of each sample solution was mixed with $2.5 \mathrm{~mL} \mathrm{~K} \mathrm{~K}_{3} \mathrm{Fe}(\mathrm{CN})_{6}$ (Cat. No. \#104971, Merck, Darmstadt, Germany) solution (1\% w/v), followed by $2.5 \mathrm{~mL}$ phosphate buffer (200 mM, pH 6.6). The mixture was incubated in a water bath for 20 minutes at $50^{\circ} \mathrm{C}$. Into the mixture, trichloroacetic acid (Cat. No. \#T6399, Sigma-Aldrich) solution (2.5 mL, 10\% w/v) was added and centrifuged for $10 \mathrm{~min}$ at $3000 \mathrm{rpm}$. The upper layer of the solution $(2.5 \mathrm{~mL})$ was taken out and mixed with water $\left(2.5 \mathrm{~mL}\right.$ ) and $\mathrm{FeCl}_{3}$ (Cat. No. \#sc215192, Santa Cruz Biotechnology) solution (0.5 mL, 0.1\% w/v). The absorbance of each sample was read at $700 \mathrm{~nm}$ by spectrophotometer and compared with the standards.

\section{Total Antioxidant Activity/Phosphomolybdate Assay}

Total antioxidant activity of GA, QUE, and RUT was determined according to a phosphomolybdate method reported previously ${ }^{19}$. Phosphomolybdate reagent contained sulfuric acid (0.6 M), sodium phosphate (28 $\mathrm{mM})$, and ammonium molybdate solution ( $4 \mathrm{mM})$. Into $3 \mathrm{~mL}$ of this solution was added $0.3 \mathrm{~mL}$ compound solution of standards (ascorbic acid and BHT) in water (50, 100, 200 and 400 $\mu \mathrm{g} / \mathrm{mL}$ ) placed in capped tubes. The reaction mixture was incubated in water bath at $95^{\circ} \mathrm{C}$ for 1.5 hours and let to cool at ambient temperature. The absorbance was measured at $695 \mathrm{~nm}$ using a spectrophotometer and the reading was compared with the standards.

\section{$\alpha$-Glucosidase Inhibitory Activity}

The $\alpha$-glucosidase inhibitory activities of GA, QUE, RUT, and acarbose (Cat. No. \#1000521, USP, North Bethesda, USA) as standard compound were carried out according to previous study. ${ }^{20}$ Briefly, a $50 \mu \mathrm{L}$ of compound solution at different concentrations was mixed with $50 \mu \mathrm{L}$ phosphate buffer ( $50 \mathrm{mM}, \mathrm{pH} 6.8$ ) and $50 \mu \mathrm{L}$ of $\alpha$-glucosidase (Cat. No. \#G5003, Sigma-Aldrich) (0.5 unit $/ \mathrm{mL})$. After preincubating for $5 \mathrm{~min}$ at $37^{\circ} \mathrm{C}$, substrate $(1 \mathrm{mM}$ p-nitrophenol$\alpha$-D glucopyranoside) (Cat. \#N1377, Sigma-Aldrich) was added to the reaction mixture and incubated for $20 \mathrm{~min}$ at $37^{\circ} \mathrm{C}$. The reaction was stopped by adding $750 \mu \mathrm{L} \mathrm{Na}_{2} \mathrm{CO}_{3}$ $(100 \mu \mathrm{M})$. The absorbance was read at $405 \mathrm{~nm}$. For the control solution, all procedures were followed except that sample was replaced by buffer. The percentage of inhibition was calculated using the following equation:

$$
\alpha \text {-Glucosidase inhibition }(\%)=\frac{\mathrm{A}_{\text {control }}-\mathrm{A}_{\text {sample }}}{\mathrm{A}_{\text {control }}} \times 100 \%
$$

Where $\mathrm{A}_{\text {control }}$ : absorbance of control, $\mathrm{A}_{\text {sample }}$ : absorbance of sample. The $\alpha$-glucosidase inhibitory activity was expressed as $\mathrm{IC}_{50}$ values $(\mu \mathrm{g} / \mathrm{mL})$ and was determined from the graph plotted against the percentage inhibition. Values were compared with the positive control acarbose, the antidiabetic medicine.

\section{Enzyme Kinetic Assay}

GA, QUE, RUT and the positive control, acarbose were evaluated for their inhibitory kinetics on $\alpha$-glucosidase activity according to a method described previously. ${ }^{18}$ The inhibition type was determined based on the effect of different concentrations of each compound on increasing concentration of 4-Nitrophenyl- $\beta$-D-glucopyranoside (p-NPG) (0.25-1.25 mM) as substrate. The study of the inhibition type (competitive, uncompetitive, noncompetitive or mixed) was performed using the nonlinear regression Michaelis-Menten enzyme kinetics and the corresponding Lineweaver-Burk double reciprocal plots (1/Vmax vs $1 /[\mathrm{S}]$, as $\mathrm{y}$ and $\mathrm{x}$ axis, respectively) for each concentration of the inhibitor and substrate. The Ki values were calculated with Molecular Operating Environment Software.

\section{Preparation of Ligands}

GA, QUE, RUT, and acarbose were compounds to be used for molecular docking simulations on $\alpha$-glucosidase. All of the two dimensional (2D) structures of the compounds 
were retrieved from PubChem database as an .sdf file and were imported into MOE 2010.10 and save as a .pdb file. The three dimensional (3D) structures of all ligands were obtained from PubChem database with PubChem CID 370 (GA), 41774 (acarbose), 5280343 (QUE), and 5280805 (RUT). The optimization of these ligands was performed using a Merck molecular force field MMFF94x in MOE.

\section{Molecular Modelling (of $\alpha$-Glucosidase, GA, QUE, RUT, and Acarbose)}

The 3D structures of Saccharomyces cerevisiae $\alpha$-glucosidase are not reported yet. However, the crystal structure that has been isolated for Saccharomyces cerevisiae is of manosyl-oligosaccahride glucosidase. The amino acid sequence of this protein was obtained from NCBI data base (http://www.ncbi.nlm.nih.gov/protein/) and the 3D model was built using SWISS-MODEL server and the predicted template of 3D model was obtained from Protein Data Bank. The 3D structures of the protein were validated using Ramachandran plot.

\section{Molecular Docking of GA, QUE and RUT with a-Glucosidase}

Before the molecular docking was performed, the following preparations were conducted, such as addition of hydrogen atoms and/or partial charges to the model and minimization of unwanted steric effect by keeping heavy atoms fixed. The target receptors model of $\alpha$-glucosidase energy was optimized using CHARMM in MOE. Molecular docking between ligand and target receptors was performed on the active site generated from the MOE-Alpha Site Finder module using a wall constraint with radius $7 \AA$. The molecular docking itself was carried out using Triangle Matcher placement method and a force field refinement. Docking poses were scored using the Affinity $\Delta \mathrm{G}$ scoring method of MOE. Selection of lead compound was performed by analyzing the residue interactions, hydrogen bonds, and electrostatic interactions generated from molecular docking.

\section{Statistical Analysis}

All experiments were carried out in triplicates. Results were reported as mean \pm standard deviation (SD). Regression method was used to calculate $\mathrm{IC}_{50}$ and enzymatic kinetic.

\section{Results}

Three different methods were used to evaluate the antioxidant activity of GA, QUE and RUT. For each method, ascorbic acid and BHT as standards were also assessed to compare the activity.

DPPH assay was the method used to assess the radical scavenging activity of the compounds. Scavenging free radicals is an important mechanism involving antioxidant pathway. The results for radical scavenging activities $\left(\mathrm{IC}_{50}\right)$ are shown in Table 1. QUE was the best scavenger/ antioxidant among other compounds (GA, RUT, AA and BHT). In addition to DPPH assay, the antioxidant activity of the compounds was also evaluated based on reducing power and total antioxidant activity. In this case, an electron is donated from the antioxidant compounds to reduce Fe(III) to $\mathrm{Fe}(\mathrm{II})$ or $\mathrm{Mo}(\mathrm{VI})$ to $\mathrm{Mo}(\mathrm{V})$ for reducing power and total antioxidant activity assay, respectively. Results are shown in Figure 2. Based on these methods, generally, the activities of the compounds showed the following order: AA $>$ GA $>$ BHT $>$ QUE $>$ RUT.

The $\alpha$-glucosidase inhibition activity of the compounds was investigated, and the results are shown in Table 2. All the tested compounds, GA, QUE and RU, showed excellent inhibition activity on $\alpha$-glucosidase compared to that of the standard acarbose, as indicated by their $\mathrm{IC}_{50}(\mu \mathrm{g} / \mathrm{mL})$. Their

Table 1. Comparative DPPH radical scavenging activities of GA, QUE, RUT and standards $\left(\mathrm{IC}_{50}\right)$.

\begin{tabular}{|c|c|c|c|}
\hline \multicolumn{2}{|c|}{$\begin{array}{c}\text { Concentration } \\
(\mu \mathrm{g} / \mathrm{mL})\end{array}$} & \multirow{2}{*}{$\begin{array}{c}\begin{array}{c}\text { Inhibition } \\
(\mathbf{\%})\end{array} \\
20.12 \pm 0.01\end{array}$} & \multirow{2}{*}{$\begin{array}{c}\begin{array}{c}\mathbf{I C}_{\mathbf{5 0}} \\
(\boldsymbol{\mu g} / \mathbf{m L})\end{array} \\
58.82 \pm 0.37\end{array}$} \\
\hline Gallic Acid & 10 & & \\
\hline & 15 & $24.14 \pm 0.09$ & \\
\hline & 25 & $33.31 \pm 0.09$ & \\
\hline & 43.75 & $39.05 \pm 0.22$ & \\
\hline & 62.5 & $52.79 \pm 0.16$ & \\
\hline \multirow[t]{5}{*}{ Quercetin } & 1 & $18.02 \pm 0.19$ & $2.71 \pm 0.04$ \\
\hline & 2 & $29.36 \pm 4.11$ & \\
\hline & 2.5 & $39.32 \pm 0.43$ & \\
\hline & 3 & $69.71 \pm 0.20$ & \\
\hline & 3.75 & $74.20 \pm 0.61$ & \\
\hline \multirow[t]{5}{*}{ Rutin } & 5 & $25.42 \pm 0.14$ & $8.53 \pm 0.01$ \\
\hline & 6.25 & $33.22 \pm 0.05$ & \\
\hline & 7.5 & $41.17 \pm 0.08$ & \\
\hline & 10 & $62.76 \pm 0.16$ & \\
\hline & 12.5 & $77.33 \pm 0.10$ & \\
\hline \multicolumn{2}{|l|}{ Ascorbic acid } & & $53.24 \pm 0.82$ \\
\hline \multicolumn{2}{|l|}{ BHT } & & $21.36 \pm 0.80$ \\
\hline
\end{tabular}


A

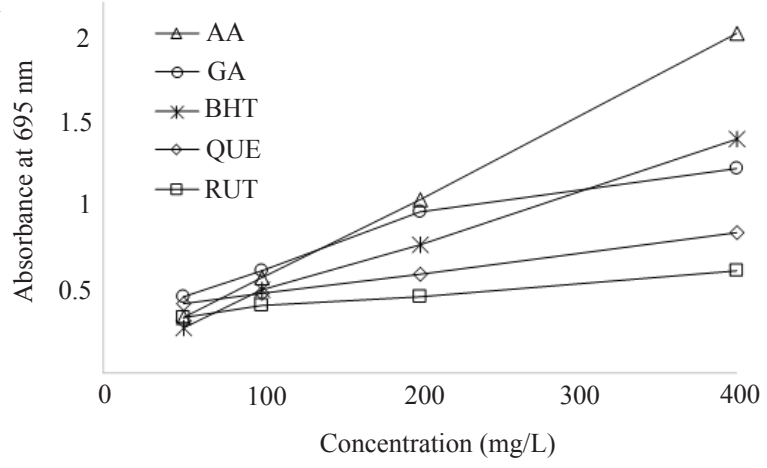

B

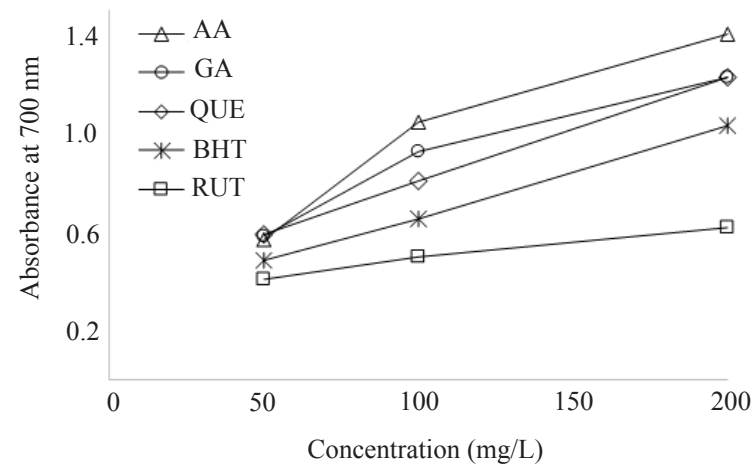

Figure 2. Antioxidant activity measured by phosphomolybdate (A) and reducing power assay (B).

$\mathrm{IC}_{50}$ values were in the range of 65.52 to 224.55 , lower than $\mathrm{IC}_{50}$ of acarbose of 823.00 (Table 2). It was evident that QUE was the most active inhibitor.

To characterize the type of inhibition of the compounds on $\alpha$-glucosidase, i.e., competitive, noncompetitive, uncompetitive, or mixed, the Linewaver-Burk double reciprocal plots were generated. The results were shown in Figure 3. The LB plots of GA, RUT, and acarbose gave straight lines which had different intersection on the $\mathrm{X}$-axis. These results suggest a competitive inhibition on $\alpha$-glucosidase by these compounds. Different result was observed for QUE. In the presence of increasing concentrations of QUE, the Lineweaver-Burk plot generated straight lines which had

Table 2. IC ${ }_{50}$ of $\alpha$-glucosidase inhibition by GA, QUE and RUT.

\begin{tabular}{lccc}
\hline \multicolumn{2}{c}{$\begin{array}{c}\text { Concentration } \\
(\mu \mathrm{g} / \mathrm{mL})\end{array}$} & $\begin{array}{c}\text { Inhibition } \\
(\%)\end{array}$ & $\begin{array}{c}\text { IC }_{\mathbf{5 0}} \\
(\boldsymbol{\mu g} / \mathbf{m L})\end{array}$ \\
\hline Gallic Acid & 200 & $16.34 \pm 2.00$ & $220.12 \pm 5.05$ \\
& 210 & $25.84 \pm 5.58$ & \\
& 225 & $74.98 \pm 1.76$ & \\
\hline Quercetin & 250 & $89.91 \pm 10.84$ & \\
& 25 & $19.46 \pm 6.71$ & $65.52 \pm 2.88$ \\
& 50 & $32.99 \pm 0.44$ & \\
\hline Rutin & 75 & $72.22 \pm 2.78$ & \\
& 125 & $84.07 \pm 1.60$ & \\
& 200 & $26.99 \pm 3.94$ & $224.55 \pm 5.48$ \\
& 225 & $50.7 \pm 9.96$ & \\
\hline Acarbose & 250 & $75.57 \pm 2.54$ & \\
\hline & 275 & $92.81 \pm 2.54$ & \\
\hline
\end{tabular}

a point of intersection in the second quadrant, indicating that the inhibition was of the mixed competitive and noncompetitive type.

The molecular docking studies were conducted in order to understand the binding interaction between inhibitors and the enzyme $\alpha$-glucosidase. Table 3 shows the binding energy of four different ligands and the receptor, together with the kind of interaction and bond lengths. The docking simulations are shown in Figure 4.

\section{Discussion}

According to Niedowicz, oxidative stress may contribute to the incidence of oxidative related complications in diabetes. ${ }^{21}$ Long term hyperglycemia may induce increased production of reactive oxygen species (ROS) via non-enzymatic glucose autoxidation, glycation, and alterations in poly-ol pathway activity. ${ }^{22}$ Therefore, in the present study, the antioxidant properties of GA, QUE, and RUT were evaluated and compared. Phytochemicals that possess antioxidant properties were reported to exert their antioxidative mechanism by way of reducing oxidative species. ${ }^{23}$ The current study evaluated the reducing properties of the compounds by their ability to reduce $\mathrm{Fe}(\mathrm{III})$ to $\mathrm{Fe}(\mathrm{II})$ and $\mathrm{Mo}(\mathrm{VI})$ to $\mathrm{Mo}(\mathrm{V})$. These assays reflect the reducing capability of antioxidant compounds and may serve as a significant indicator for antioxidant activity. ${ }^{24}$ In both assays, the results revealed that GA possessed the strongest reducing capacity compared to QUE and RUT. Furthermore, the current study also evaluated antioxidant properties of the tested compounds based on their free radical scavenging ability. The result found that QUE and RUT (flavonoids) were stronger radical scavengers than GA (a phenolic compound). The different results obtained 

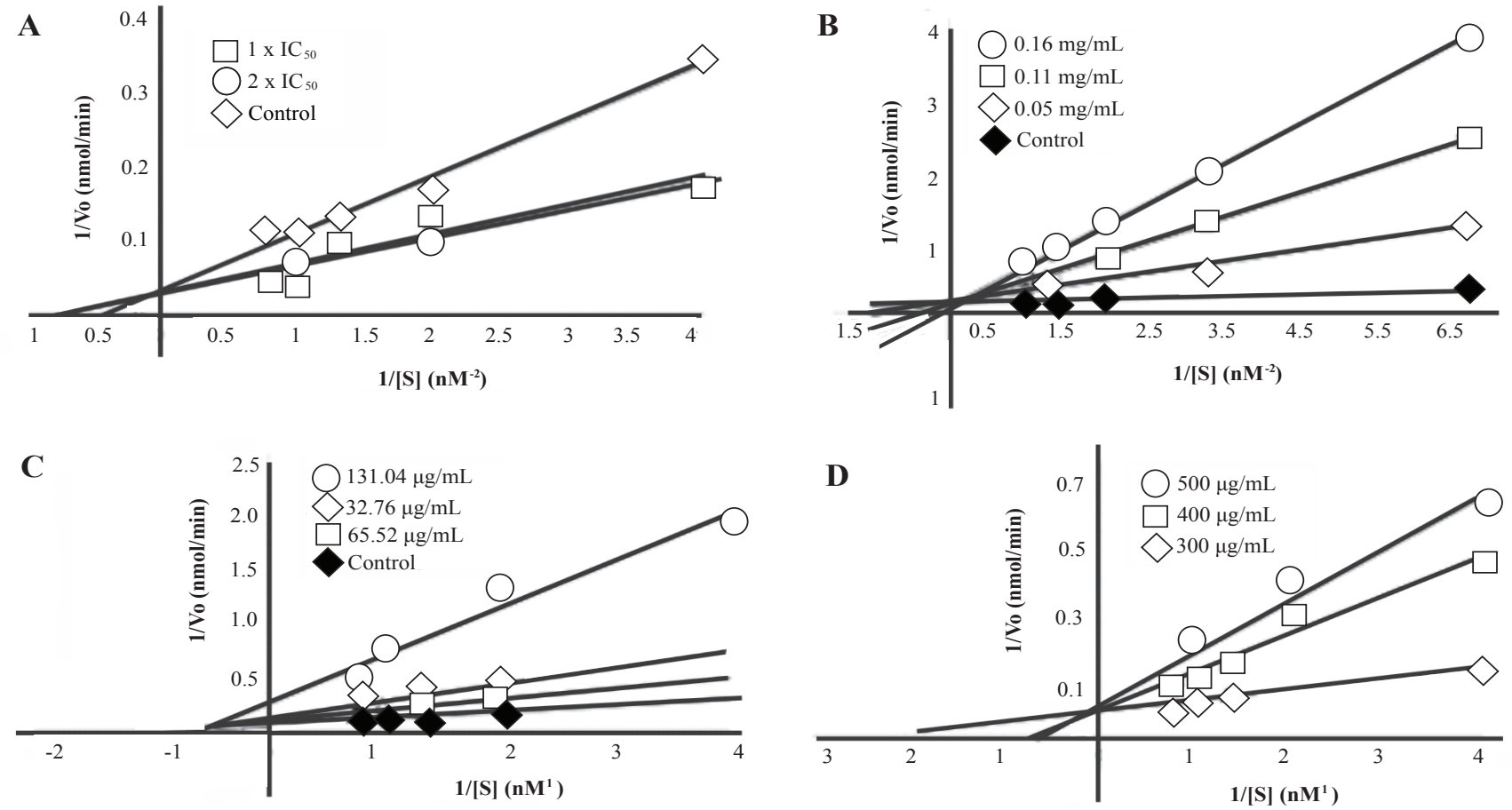

Figure 3. Lineweaver-Burk plot of GA (A), Acarbose (B), QUE (C), and RUT (D) on $\alpha$-glucosidase at different concentration of p-NPG.

in reducing power and DPPH assays could be due to the difference in antioxidant mechanism that took place in the assays. According to Celik and Arinç, quercetin expressed higher antioxidant capacity than its flavonoids derivatives, like rutin and naringenin. ${ }^{25}$ Heijnen, et al., reported that the presence of multiple hydroxyl groups of flavonoid act as vigorous scavengers not only for ROS but also for RNS. ${ }^{26}$ The hydroxyl groups dominate the capability of flavonoids as antioxidant. ${ }^{10}$

Diabetes mellitus is characterized by postprandial hyperglycemia over a prolonged period, which may be due to resistance to insulin action and/or inadequate

Table 3. Energy calculation and H-bond parameter.

\begin{tabular}{|c|c|c|c|c|c|}
\hline & $\begin{array}{c}\Delta G \\
(\text { kcal } / \text { mol) }\end{array}$ & $\begin{array}{c}K_{\mathbf{i}} \\
(\mathrm{M})\end{array}$ & Interaction & Residue & $\begin{array}{c}\text { Distance } \\
(\AA)\end{array}$ \\
\hline \multirow{2}{*}{ Quercetin } & \multirow{2}{*}{-6.6711} & \multirow{2}{*}{12.8} & H-donor & Glu 411 & 3.23 \\
\hline & & & H-donor & Asp 215 & 2.88 \\
\hline \multirow{5}{*}{ Rutin } & \multirow{5}{*}{-8.7832} & \multirow{5}{*}{0.361464} & H-donor & Asp 242 & 2.74 \\
\hline & & & H-donor & Ser 311 & 2.78 \\
\hline & & & H-donor & Leu 313 & 3.01 \\
\hline & & & H-donor & $\operatorname{Gln} 279$ & 2.79 \\
\hline & & & H-donor & Glu 411 & 2.98 \\
\hline \multirow{3}{*}{ Gallic Acid } & \multirow{3}{*}{-4.4458} & \multirow{3}{*}{548.76} & H-acceptor & Ser 240 & 3.3 \\
\hline & & & H-acceptor & Ser 241 & 3.1 \\
\hline & & & H-pi & Tyr 158 & 3.49 \\
\hline Acarbose & -5.668 & 69.664 & H-donor & Asp 242 & 2.91 \\
\hline
\end{tabular}


A

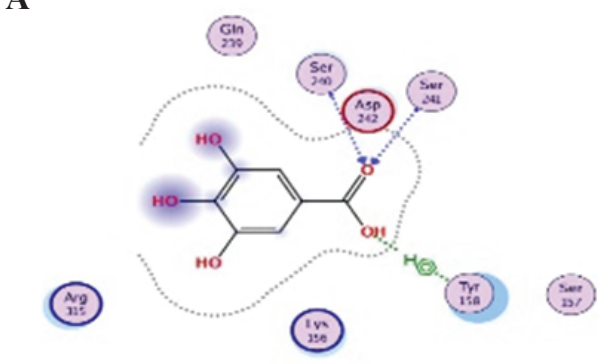

C

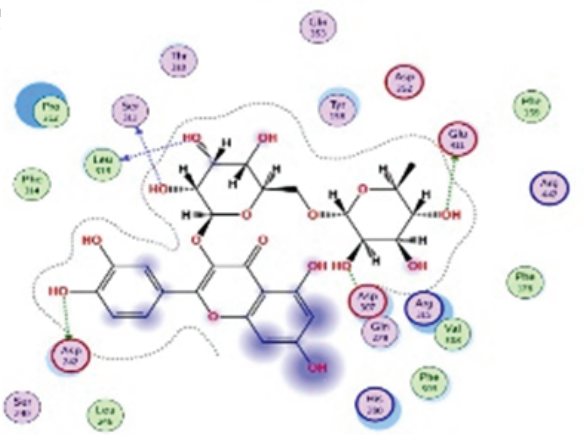

B

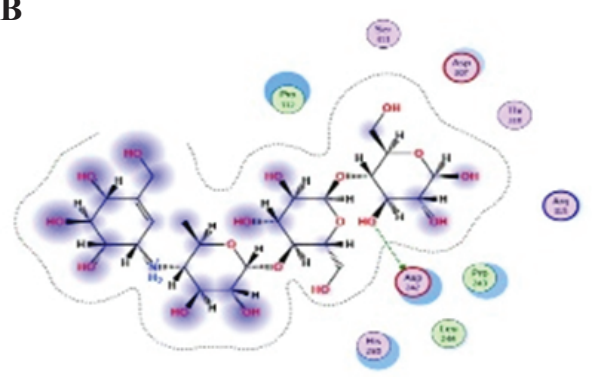

D

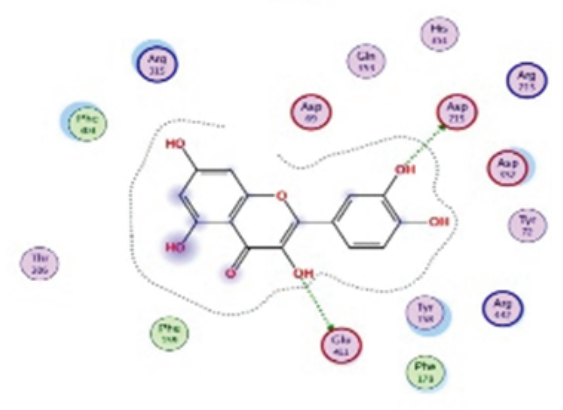

Figure 4. Two-dimension (2D) simulation by docking analysis for Acarbose (A), GA (B), QUE (C) and RUT (D).

insulin secretion. ${ }^{27}$ Inhibition of digestive enzymes (such as $\alpha$-glucosidase and $\alpha$-amylase) that hydrolyze dietary polysaccharide into glucose is crucial for controlling glucose blood level. Therefore, inhibitors that target $\alpha$-glucosidase serve as a key strategy in the treatment of diabetes mellitus. In the present work, the potential inhibition of the compounds on $\alpha$-glucosidase activity was evaluated.

All compounds showed significant inhibition on $\alpha$-glucosidase compared to acarbose, with QUE almost 13 times more active than acarbose, whereas GA and RUT almost 4 times stronger than acarbose. Through the enzyme kinetic study, GA and RUT were shown to act as competitive inhibitors on $\alpha$-glucosidase, similar to that found for acarbose. These results suggest that GA, RUT, and acarbose inhibited $\alpha$-glucosidase by binding with free enzyme in a manner that prevents substrate binding. These findings are in accordance with previous studies by Zhang, et al, and Proença, et al. ${ }^{28,29}$ On the other hand, QUE inhibited $\alpha$-glucosidase in a mixed type of competitive and noncompetitive inhibition. This observation indicates that QUE may form enzyme-inhibitor complex and form substrate - inhibitor to interrupt enzyme-substrate intermediate. It is likely that the mixed type inhibition enables QUE to inhibit $\alpha$-glucosidase in a broader binding sites compared to GA, RUT and acarbose as competitive inhibitors, giving rise to the lowest $\mathrm{IC}_{50}$ value observed for QUE.
In order to further understand the binding mechanism at molecular level, molecular docking analysis was performed between $\alpha$-glucosidase and each compound. In all ligand-receptor models, the hydrogen bonds are the main drivers involved for the interaction of each docked ligand to $\alpha$-glucosidase. At $\alpha$-glucosidase binding site, GA showed two H-interactions with Ser240 and Ser241, and one interaction of H-pi with Tyr158. Two H-bonds were observed between QUE and active site residues Glu411 and Asp215. Five H-bonds were formed between RUT with the amino acid residues Asp242, Ser311, Leu313, Gln279 and Glu411, whereas the competitive inhibitor acarbose showed one H-bond interaction with Asp242. It is worth pointing that GA, RUT and acarbose occupy the same active sites at $\alpha$-glucosidase to avoid the entrance of the substrate pNPG. The binding sites observed by docking simulations supported the competitive type of inhibition obtained from kinetic experimental assay for these compounds.

The docking energy calculated for all the tested compounds further supported the experimental results. The predicted free energy calculated for GA, QUE, and RUT were lower than acarbose. This result confirms the stronger inhibitory activities of these compounds on $\alpha$-glucosidase when compared with acarbose. In addition, the predicted Ki values for QUE and RUT ( $\mathrm{Ki}=12.8$ and 0.36 , respectively) were also lower than acarbose $(\mathrm{Ki}=69.66)$, indicating 
that QUE and RUT have more affinity for $\alpha$-glucosidase compared to acarbose.

\section{Conclusion}

The present study found that flavonoids like QUE and RUT are good antioxidants. QUE and RUT are also good inhibitors for $\alpha$-glucosidase activity, with inhibition activities better than the standard compound acarbose, thus can be effective in reducing post-prandial hyperglycemia (PPHG). These findings may facilitate further research for the development and application of these compounds as $\alpha$-glucosidase inhibitors and ingredients in functional food.

\section{Acknowledgement}

We are grateful to the Faculty of Medicine and the Research Institute of Krida Wacana Christian University, for supporting this project financially and institutionally.

\section{References}

1. Yan J, Zhang G, Pan J, Wang Y. $\alpha$-Glucosidase inhibition by luteolin: Kinetics, interaction and molecular docking. Int J Biol Macromol. 2014; 64: 213-23

2. Peng X, Zhang G, Liao Y, Gong D. Inhibitory kinetics and mechanism of kaempferol on $\alpha$-glucosidase. Food Chem. 2016; 190: 207-15.

3. Oboh G, Ogunsuyi OB, Ogunbadejo MD, Adefegha SA. Influence of gallic acid on $\alpha$-amylase and $\alpha$-glucosidase inhibitory properties of acarbose. J Food Drug Anal. 2016; 24(3): 627-34.

4. Zanwar AA, Badole SL, Shende PS, Hegde MV, Bodhankar SL. Role of gallic acid in cardiovascular disorders. In: Watson RR, Preedy VR, Zibadi S, eds. Polyphenols in Human Health and Disease: Amsterdam: Elsevier; 2014. p.1045-7.

5. Ademiluyi AO, Oboh G, Aragbaiye FP, Oyeleye SI, Ogunsuyi OB. Antioxidant properties and in vitro $\alpha$-amylase and $\alpha$-glucosidase inhibitory properties of phenolics constituents from different varieties of Corchorus spp. J Taibah Univ Med Sci. 2015; 10(3): 278-87.

6. Abdel-Moneim A, El-Twab SMA, Yousef AI, Reheim ESA, Ashour MB. Modulation of hyperglycemia and dyslipidemia in experimental type 2 diabetes by gallic acid and p-coumaric acid: The role of adipocytokines and PPAR $\gamma$. Biomed Pharmacother. 2018; 105: 1091-7.

7. Kamiyama O, Sanae F, Ikeda K, Higashi Y, Minami Y, Asano N, et al. In vitro inhibition of $\alpha$-glucosidases and glycogen phosphorylase by catechin gallates in green tea. Food Chem. 2010; 122(4): 1061-6.

8. You Q, Chen F, Wang X, Jiang Y, Lin S. Anti-diabetic activities of phenolic compounds in muscadine against alpha-glucosidase and pancreatic lipase. LWT-Food Sci Technol. 2012; 46(1): 164-8.

9. Benalla W, Bellahcen S, Bnouham M. Antidiabetic medicinal plants as a source of alpha glucosidase inhibitors. Curr Diabetes Rev. 2010; 6(4): 247-54.

10. Banjarnahor SDS, Artanti N. Antioxidant properties of flavonoids. Med J Indones. 2014; 23(4): 5. doi: 10.13181/mji.v23i4.1015.
11. Chen C, Zhou J, Ji C. Quercetin: a potential drug to reverse multidrug resistance. Life Sci. 2010; 87(11-12): 333-8.

12. Ghorbani A. Mechanisms of antidiabetic effects of flavonoid rutin. Biomed Pharmacother. 2017; 96: 305-12.

13. Jo S, Ka E, Lee H, Apostolidis E, Jang H, Kwon Y. Comparison of antioxidant potential and rat intestinal a-glucosidases inhibitory activities of quercetin, rutin, and isoquercetin. Int J App Res Nat Prod. 2009; 2(4): 52-60.

14. Shi GJ, Li Y, Cao QH, Wu HX, Tang XY, Gao XH, et al. In vitro and in vivo evidence that quercetin protects against diabetes and its complications: a systematic review of the literature. Biomed Pharmacother. 2019; 109: 1085-99.

15. Youl E, Bardy G, Magous R, Cros G, Sejalon F, Virsolvy A, et al. Quercetin potentiates insulin secretion and protects INS-1 pancreatic $\beta$-cells against oxidative damage via the ERK1/2 pathway. Br J Pharmacol. 2010; 161(4): 799-814.

16. Li YQ, Zhou FC, Gao F, Bian JS, Shan F. Comparative evaluation of quercetin, isoquercetin and rutin as inhibitors of $\alpha$-glucosidase. J Agric Food Chem. 2009; 57(24): 11463-8.

17. Timotius KH, Simamora A, Santoso AW. Chemical characteristics and in vitro antidiabetic and antioxidant activities of Premna serratifolia L. leaf infusion and decoction. Pharmacog J. 2018; 10(6): 1114-8.

18. Simamora A, Paramita L, Mohamad Hamid NAB, Santoso AW, Timotius KH. In vitro antidiabetic and antioxidant activities of aqueous axtract from the leave and fruit of Psidium guajava $\mathrm{L}$. Indones Biomed J 2018; 10(2): 156-64.

19. Khatoon M, Islam E, Islam R, Rahman AA, Alam AK, Khondkar P, et al. Estimation of total phenol and in vitro antioxidant activity of Albizia procera leaves. BMC Res Notes. 2013; 6(1): 121.

20. Simamora A, Adit Widodo S, Kris Herawan T. Bioactivities of methanol and ethyl acetate mace extracts of Myristica fragrans Houtt. Pharmacognosy Communications. 2018; 8(3): 103-7.

21. Niedowicz DM, Daleke DL. The role of oxidative stress in diabetic complications. Cell Biochem Biophys. 2005; 43(2): 289-330.

22. King GL, Loeken MR. Hyperglycemia-induced oxidative stress in diabetic complications. Histochem Cell Biol. 2004; 122(4): 333-8.

23. Islam MM. Biochemistry, medicinal and food values of jute (Corchorus capsularis L. and C. olitorius L.) leaf: a review. Int J Enhanc Res Sci Technol Eng. 2013; 2(11): 35-44.

24. Gulcin I, Elmastas M, Aboul-Enein HY. Determination of antioxidan and radical scavenging activity of Basil (Ocimum basilicum L. Family Lamiaceae) assayed by different methodologies. Phytother Res. 2007; 21(4): 354-61.

25. Çelik H, Arinç E. Evaluation of the protective effects of quercetin rutin, naringenin, resveratrol and trolox against idarubicin-induced DNA damage. J Pharm Pharm Sci. 2010; 13(2): 231-41.

26. Heijnen C, Haenen G, Van Acker F, Van der Vijgh W, Bast A. Flavonoids as peroxynitrite scavengers: the role of the hydroxyl groups. Toxicol In Vitro. 2001; 15(1): 3-6

27. American Diabetes Association. Diagnosis and classification of diabetes mellitus. Diabetes Care. 2004; 27(Suppl 1): s5-s10.

28. Zhang BW, Sang YB, Sun WL, Yu HS, Ma BP, Xiu ZL, et al. Combination of flavonoids from Oroxylum indicum seed extracts and acarbose improves the inhibition of postprandial blood glucose: In vivo and in vitro study. Biomed Pharmacother. 2017; 91: 890-8.

29. Proença C, Freitas M, Ribeiro D, Oliveira EF, Sousa JL, Tomé SM, et al. $\alpha$-Glucosidase inhibition by flavonoids: an in vitro and in silico structure-activity relationship study. J enzyme inhibit med chem. 2017; 32(1): 1216-28. 